\title{
Geothermal gradient and heat flow data in and around Japan (II): Crustal thermal structure and its relationship to seismogenic layer
}

\author{
Akiko Tanaka \\ Geological Survey of Japan, National Institute of Advanced Industrial Science and Technology, AIST Tsukuba Central 7 , \\ 1-1-1 Higashi, Tsukuba, Ibaraki 305-8567, Japan
}

(Received June 8, 2004; Revised October, 19, 2004; Accepted November 3, 2004)

\begin{abstract}
The high-quality database of seismicity of Japan (JMA, Japan Meteorological Agency) and an extensive compilation of thermal measurements (Tanaka et al., 2004a) are used to quantify the concept of temperature as a fundamental parameter for determining the thickness of the seismogenic zone. Qualitative comparisons between each data of heat flow and geothermal gradient, and the lower limit of crustal earthquake hypocentral distributions beneath the Japanese Islands show that, as expected, the lower limit of seismicity is inversely related to heat flow and geothermal gradient. However, the density of the data is not uniform but highly clustered and spatially concentrated instead. To fill the data gaps, the available data were interpolated onto regular grids of points with a spacing of $0.25^{\circ} \times 0.25^{\circ}$. Gridded heat flow or geothermal gradient and $\mathrm{D}_{90}$, the depth above which $90 \%$ of earthquakes occur, correlated well with each other. The evaluated temperatures for $\mathrm{D}_{90}$ range between $250^{\circ} \mathrm{C}$ and $450^{\circ} \mathrm{C}$ except for higher heat flow data. The consistency of temperature for $\mathrm{D}_{90}$ over a large depth interval almost all over the Japanese Islands support the concept that the temperature is the dominant factor governing the focal depth in the crust. A comparison of our results with other tectonic regions could provide evidence for variations in temperatures for $\mathrm{D}_{90}$.
\end{abstract}

Key words: Heat flow, geothermal gradient, thermal structure, seismogenic layer, Japan.

\section{Introduction}

Laboratory studies of the transition from unstable to stable sliding in rocks provide strong evidence for the importance of temperature in determining the maximum nucleation depth of large earthquakes (Blanpied et al., 1995). Thermal models must incorporate the considerations of geotherms from surface heat flow data. Complications in the crustal thermal model arise from contrast of lithologies and fluid flow. Furthermore, due to uncertainties in crustal heat production, the geotherms are ambiguous. Therefore, many studies focus on the correlation between the seismicity depth and heat flow, rather than the temperature at depth. Relationships between continental heat flow and the depth of the seismogenic zone provided evidence of an inverse correlation (e.g., Sibson, 1982; Ito, 1990). The higher the heat flow, the shallower the depth of seismogenic zone. This correlation is confirmed and quantified using carefully determined heat flow data for the San Andreas Fault (Williams, 1996) and the Western Nagano area (Tanaka and Ito, 2002). Although this relationship seems to be plausible, uneven data distribution preclude improving on the general correlation between heat flow and the depth of the seismogenic zone over some regional areas.

The Japanese Islands, because of its abundant, welllocated seismicity and well-characterized heat flow, provide an excellent natural laboratory for improving this limita-

Copy right(c) The Society of Geomagnetism and Earth, Planetary and Space Sciences (SGEPSS); The Seismological Society of Japan; The Volcanological Society of Japan; The Geodetic Society of Japan; The Japanese Society for Planetary Sciences; TERRAPUB tion. In this paper, we used the recently published compilation of thermal data (Tanaka et al., 2004a) to show the relationship over regional areas and to address whether the seismic/aseismic transition corresponds to a critical temperature.

\section{Lower Limit of Seismogenic Layer and Crustal Thermal Regime}

A fundamental property of crustal seismicity is the depth confinement. Focal depths are restricted to the upper several tens kilometers of the crust. Beneath the Japanese Islands, earthquake foci reach less than $5 \mathrm{~km}$ in volcanic and geothermal areas, $10-30 \mathrm{~km}$ beneath several sedimentary basins, and up to $30 \mathrm{~km}$ beneath the Hidaka Mountain Range on Hokkaido, which have formed by collisional processes. Due to the large number of seismic station networks in Japan, earthquake location accuracies are fairly reliable beneath the Japanese Islands. JMA (Japan Meteorological Agency) determined good quality hypocenters by relocating earthquakes recorded since October 1997 (Ueno et al., 2002). The data set comprises the earthquakes that occurred shallower than $30 \mathrm{~km}$ between October 1997 and March 2003. Artificial events, noises and low-frequency events were eliminated. We used this re-determined data for the hypocentral distribution and selected crustal earthquakes with magnitude greater than 1 recorded more than 10 stations. Even if only high-quality locations are considered, several outliers are evident. They may be due to inaccurate locations or isolated seismic events generated by local anomalies. To avoid bias due to a few outliers, the lo- 

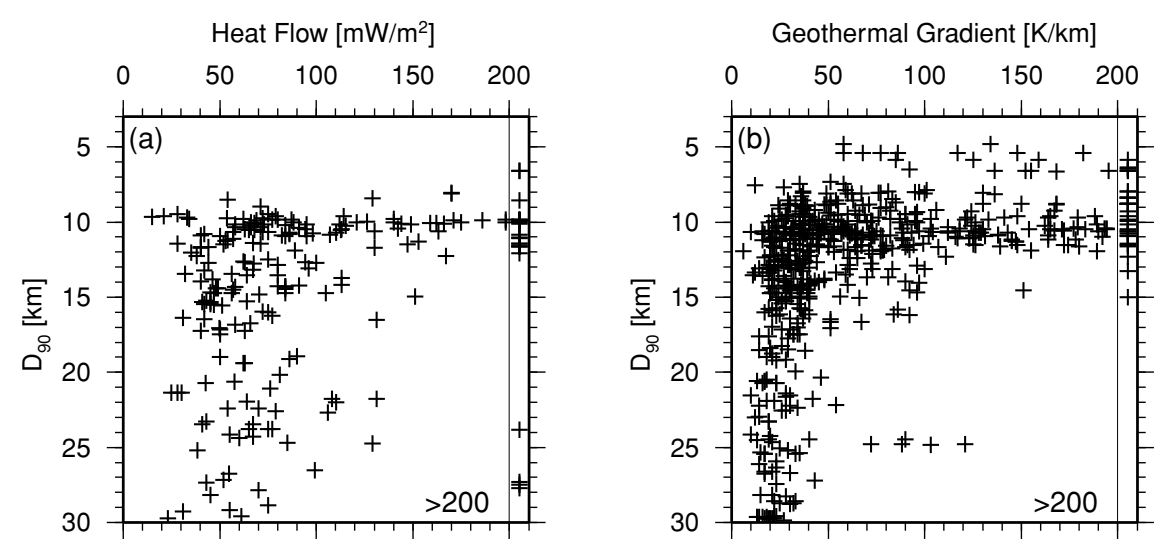

Fig. 1. (a) Heat flow and (b) geothermal gradient plotted as a function of $\mathrm{D}_{90}$, the depth above which $90 \%$ of earthquakes occur. $\mathrm{D}_{90}$ was calculated at the location of each heat flow or geothermal gradient data using seismic events within a distance of $0.1^{\circ}$. D D is reported only if more than 50 earthquakes occurred in that location.

cal maximum depth of earthquakes is defined as the depth above which 90 percent of the earthquakes occur, $\mathrm{D}_{90}$.

Surface heat flow studies and their relationship to other geophysical parameters provide useful insight on the thermal state of the crust. It is closely related to the deeper temperature regime and has direct relevance to regional tectonic interpretation. Heat flow determinations constitute the principal direct observation we have of the current crustal thermal state. Sea areas in and around Japan are generally well covered by heat flow measurements (e.g., Yamano, 1995). On land, however, heat flow data is relatively sparse. Recently updated databases of geothermal gradient data might be useful to unravel crustal thermal structure extensively (Tanaka et al., 2004b).

Figure 1(a) and (b) show the correlations between heat flow or geothermal gradient and $\mathrm{D}_{90}$. $\mathrm{D}_{90}$ was calculated for each heat flow or geothermal gradient data using seismic events within a distance of $0.1^{\circ}$. $\mathrm{D}_{90}$ is considered reliable and is reported only if more than 50 events occurred in a given domain. In general, the heat flow or geothermal gradient data show a similar pattern to $D_{90}$, with $D_{90}$ increasing with decreasing heat flow or geothermal gradient. Figure 1(a) has substantially more scatter than Fig. 1(b). Most of the scatter in Fig. 1(b) for regions with relatively deep seismicity is due to five outliers with $\mathrm{D}_{90}$ around 25 $\mathrm{km}$ and elevated geothermal gradient. The data corresponding to these outliers were collected in the Hongu area of Kii Peninsula, where Quaternary volcanoes are not known. These geothermal anomalies in non-volcanic regions were explained as effects of magma that has not erupted at the surface (Wakita et al., 1987). The heat flow and geothermal gradient data are not evenly distributed over the entire area. On land, they are collected mainly in specific areas such as volcanic and geothermal areas.

\section{Heat flow and Geothermal Gradient Data on $0.25^{\circ}$-grid}

Each data of heat flow and geothermal gradient is inversely related to $\mathrm{D}_{90}$. However, each data set is distributed unevenly geographically; some are dense, and other sparse. To estimate the regional thermal state, we used the median values of regular grids beneath the Japanese Islands. All the data sets were interpolated onto regular grids of points. The grid is at latitude and longitude with a spacing of $0.25^{\circ}$ by $0.25^{\circ}$. We find that the simple mean is inaccurate, because it is often significantly biased. By contrast, using the median of gridded heat flow or geothermal gradient distributions yields reasonable estimates of the regional heat flow, as they exclude extremely high values taken at volcanic and geothermal areas.

We considered only onland or near-shore locations because focal depths at off-shore locations are uncertain due to the spatial poor coverage of seismic stations. Figure 2(c) shows the distribution of $\mathrm{D}_{90}$ using the data with number of data more than 50 within the grid. Figure 2(a) and (b) show the medians of heat flow and geothermal gradient values, $\mathrm{HF}_{50}$ and $\mathrm{GG}_{50}$, at points on a regular rectangular grid. These maps characterize each data distributions; $\mathrm{HF}_{50}$ has a poor coverage, $\mathrm{GG}_{50}$ covers all over land area, and $\mathrm{D}_{90}$ covers land area except Hokkaido area.

Figure 3(a) and (b) provide the plots between $\mathrm{HF}_{50}$ or $\mathrm{GG}_{50}$, and $\mathrm{D}_{90}$ on grid cells of $0.25^{\circ}$ by $0.25^{\circ}$ in size. The data used to produce Fig. 3(c) are derived from heat flow distributions from measurements of heat flow and estimates from geothermal gradient (Tanaka et al., 2004b). Every plot of Fig. 3 shows the same correlation, with $\mathrm{HF}_{50}$ and $\mathrm{GG}_{50}$ decreasing with $\mathrm{D}_{90}$. Figure 3(c) is a plot similar to Fig. 3(a), but with more scatter and a less tightly correlated relationship, because the data in Fig. 3(c) involved more assumptions.

Dashed lines in Fig. 3(a) and (c) show isotherms, calculated using the steady-state, one-dimensional, heat conduction equation with an exponential decrease in the radioactivity heat generation. We estimate the isotherms using the following values: the average temperature of ground surface all over Japan is $13.51^{\circ} \mathrm{C}$ (National Astronomical Observatory, 1988); the average thermal conductivity using recently published deep boreholes data (Tanaka et al., $2004 \mathrm{a}$ ) is $3 \mathrm{~W} \mathrm{~m}^{-1} \mathrm{~K}^{-1}$; the average heat production is 1.0 $\mu \mathrm{Wm}^{-3}$ (Fowler, 1990); the characteristic thickness of the layer enriched in radioactive elements has been estimated to be about $10 \mathrm{~km}$ (Lachenbruch, 1970). These isotherms are consistent with a correlation of the seismogenic depth with heat flow. However this depth does not correspond to 


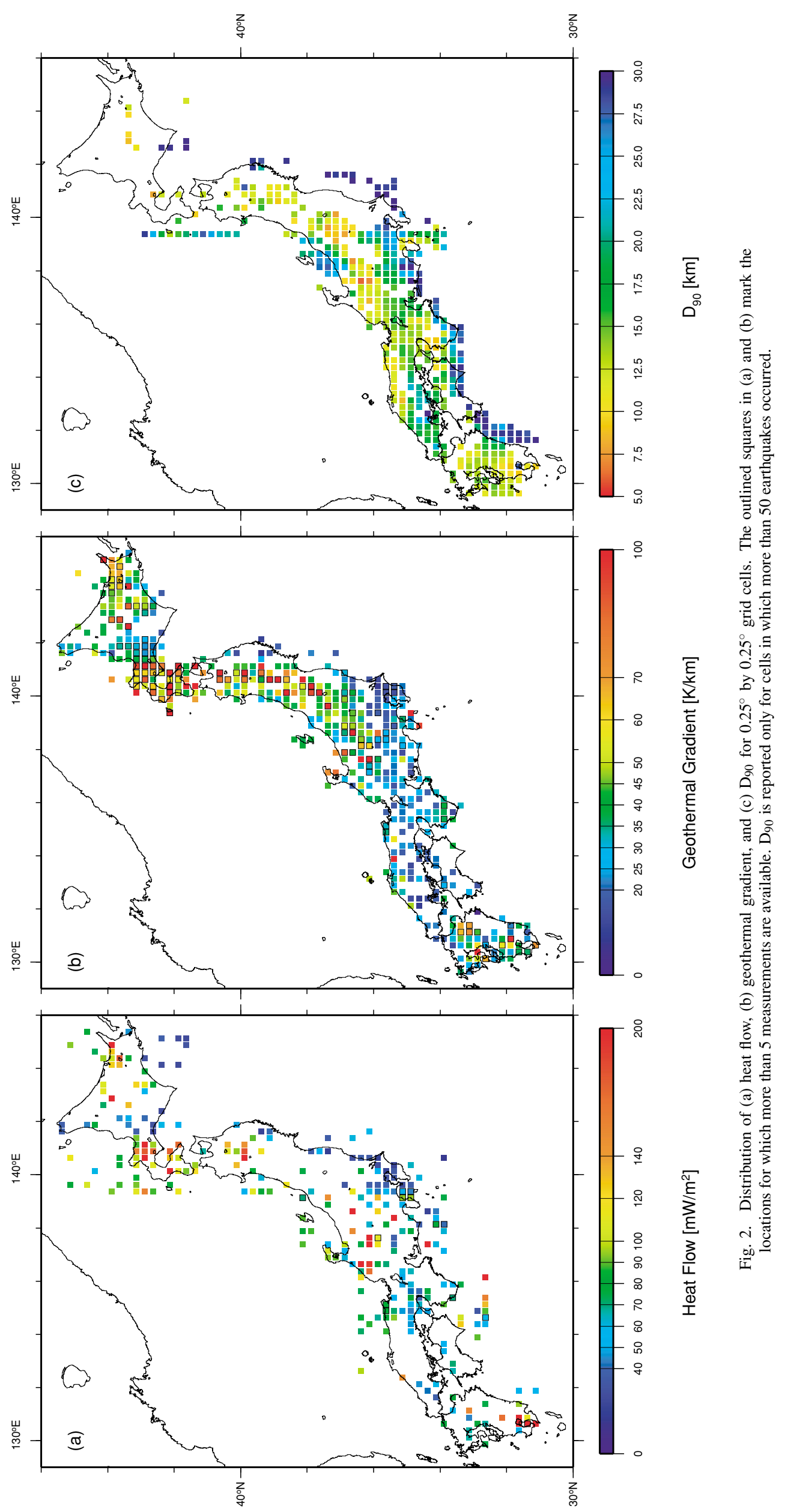



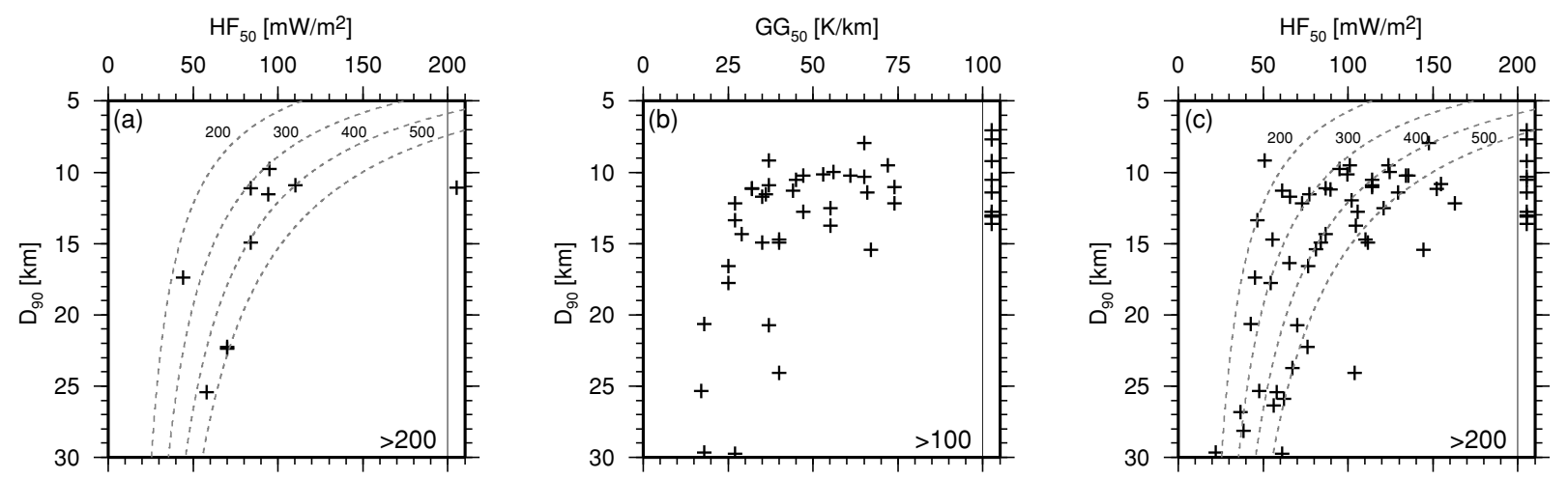

Fig. 3. Median of (a) heat flow $\left(\mathrm{HF}_{50}\right)$, (b) geothermal gradient $\left(\mathrm{GG}_{50}\right)$, and (c) estimates of heat flow derived from $\mathrm{HF}_{50}$ and geothermal gradient (from Tanaka et al., 2004a), plotted against $\mathrm{D}_{90}$. The data set was restricted to cells in which more than 5 estimates of heat flow or geothermal gradient are available and more than 50 earthquakes occurred. The gray dashed lines indicate isotherms between $200^{\circ} \mathrm{C}$ to $500^{\circ} \mathrm{C}$.

a unique temperature. With the exception of regions with heat flow in excess of $200 \mathrm{~mW} / \mathrm{m}^{2}$, where the uncertainty is greater, the temperature at $\mathrm{D}_{90}$ appears evenly distributed between 250 and $450^{\circ} \mathrm{C}$.

\section{Discussions and Conclusion}

The maximum focal depth of crustal earthquakes beneath the Japanese Islands ranges from the near surface to more than $20 \mathrm{~km}$. Many studies support that the seismogenic depth is thermally controlled. New estimates of the thermal structure of the crust, based on geothermal gradient measurements coupled with existing heat flow data, help resolving how the lower limit of seismicity varies with the thermal field. This information fill gaps in the previous heat flow coverage and allows us to better delineate the crustal thermal structure. We are combing geothermal gradient data with heat flow data to investigate possible thermal controls on crustal seismicity beneath Japanese Islands. Both heat flow and geothermal gradient shows a similar relationship, and it suggests that the pattern of the heat flow and geothermal gradient data is useful as an index of the thermal structure in the crust and $\mathrm{D}_{90}$.

Relationships using gridded data of heat flow and geothermal gradient are found to be more useful even at larger spatial scales. Using the derived heat flow from geothermal gradient in combination with observed heat flow, Figure 3(c) shows a relationship similar to Fig. 3(a), albeit with more scatter. Nevertheless, the results provide useful constraints on the relationship.

Some problems are associated with determining the seismogenic layer from seismicity data. The first is the completeness of the seismic record. It is difficult to determine whether the spatial extent of seismicity recorded over several years accurately represents the seismogenic portion of faults. The second problem is the accuracy of the focal depths themselves. The absolute uncertainty of hypocenter locations is determined by the precision of the velocity model. JMA used the same velocity model all over Japan to avoid discontinuities among velocity models. And, the limiting depth to which earthquakes are observed, may depend on focal mechanism, but it is not considered to estimate $\mathrm{D}_{90}$. These problems are involved in estimating $\mathrm{D}_{90}$, but this approach is satisfactory as a first approximation.
To quantitatively compare the data sets, the temperature for the lower limit of seismogenic zone was calculated using the steady-state, one-dimensional heat conduction equation. The consistency of the temperature at the lower limit of seismogenic zone of $250-450^{\circ} \mathrm{C}$ over a large depth interval $3-30 \mathrm{~km}$ at different locations beneath the Japanese Islands supports that temperature is the dominant factor governing the depth extent of seismogenic zone. Our results are reasonably consistent with the $300^{\circ} \mathrm{C}$ value corresponding to the onset of dislocation creep in quartz, which is assumed to control the seismic/aseismic transition zone by Scholz (1998). The variation in limiting temperature suggests that additional factors, such as strain rate, stress regime, pore pressure, and/or lithology, may contribute. For example, Blanpied et al. (1995) showed that the transition temperature should increase or decrease approximately $50^{\circ} \mathrm{C}$ with each order of magnitude increase or decrease in the fault slip rate. These could explain some of the scatter in Figs. 1 and 3. On the other hand, in oceanic intraplate environments, earthquakes are limited to temperatures around 600 $800^{\circ} \mathrm{C}$ (Wiens and Stein, 1983). Hirth (2002) showed that what limits the seismogenic zone is still controversial. And, it is still impossible to differentiate between a transition in sliding dynamics and a deformation regime.

A comparison of our results with other regions could provide evidence on possible causes for variations in the seismic-aseismic transition temperature. This transition may be controlled by a complex interaction of thermal, geological, and hydrological processes. Additional work is required to resolve this issue. The revived interest in the seismogenic depth and crustal thermal regime seems likely to continue.

Acknowledgments. The author gratefully acknowledges helpful comments and suggestions from Dr. Montesi. The author also acknowledges members of related organization (Ministry of Education, Culture, Sports, Science and Technology, National Research Institute for Earth Science and Disaster Prevention, Hokkaido University, Hirosaki University, Tohoku University, University of Tokyo, Nagoya University, Kyoto University, Kochi University, Kyushu University, Kagoshima University, National Institute of Advanced Industrial Science and Technology, Tokyo Prefecture, Hot Springs Research Institute of Kanagawa Prefecture, Shizuoka Prefecture, Yokohama City, JAMSTEC and JMA) of which high sensitivity seismogram data are transmitted to JMA, who operate 
the routine observation network, for using valuable data in this study. All figures were prepared with Generic Mapping Tools developed by Wessel and Smith (1995).

\section{References}

Blanpied, M., D. A. Lockner, and J. D. Byerlee, Frictional slip of granite at hydrothermal conditions, J. Geophys. Res., 100, 13045-13064, 1995. Fowler, C. M. R., The Solid Earth, 472 pp., Cambridge University Press, 1990.

Hirth, G., Laboratory constraints on the rheology of the upper mantle, in Plastic Deformation of Minerals and Rocks, edited by S. Karato and H.-R. Wenk, Reviews of Mineralogy and Geochemistry 51, pp. 97-120, Mineralogical Society of America, Washington, DC (USA), 2002.

Ito, K., Regional variations of the cutoff depth of seismicity in the crust and their relation to heat flow and large island earthquakes, J. Phys. Earth, 28, 223-250, 1990

Lachenbruch, A. H., Crustal temperature and heat production: Implications of the linear heat-flow relation, J. Geophys. Res., 75, 3291-3300, 1970.

National Astronomical Observatory (ed.), Rika nenpyo (Chronological Scientific Tables), 1058 pp., 1998 (in Japanese).

Scholz, C. H., Earthquakes and friction laws, Nature, 391, 37-42, 1998.

Sibson, R., Fault zone models, heat flow, and the depth distribution of earthquakes in the continental crust of the United States, Bull. Seism. Soc. Am., 72, 451-463, 1982.

Tanaka, A. and H. Ito, Temperature at the base of the seismogenic zone and its relationship to the focal depth of the western Nagano Prefecture area, J. Seism. Soc. Japan, 55, 1-10, 2002 (in Japanese with English abstract).
Tanaka, A., M. Yamano, Y. Yano, and M. Sasada, Geothermal Gradient and Heat Flow Data in and around Japan, Digital Geoscience Map DGM P5, Geological Survey of Japan, 2004a.

Tanaka, A., M. Yamano, Y. Yano, and M. Sasada, Geothermal gradient and heat flow data in and around Japan (I): Appraisal of heat flow from geothermal gradient data, Earth Planets Space, 56, this issue, 11931196, 2004b.

Ueno, S., S. Hatakeyama, T. Aketagawa, J. Funasaki, and N. Hamada, Improvement of hypocenter determination method by Japan Meteorological Agency, Kenshinjiho (Quarterly J. Seism.), 65, 123-134, 2002 (in Japanese with English abstract).

Wakita, H., Y. Sano, and M. Mizoue, High ${ }^{3} \mathrm{He}$ emanation and seismic swarms observed in a nonvolcanic forearc region, J. Geophys. Res., 92, 12539-12546, 1987.

Wessel, P. and W. H. F. Smith, New version of the Generic Mapping Tools released, Eos Trans., AGU, 76(33), 329, 1995.

Wiens, D. and S. Stein, Age dependence of oceanic intraplate seismicity and implications for lithospheric evolution, J. Geophys. Res., 88, 64556468, 1983.

Williams, C., Temperature and the seismic/aseismic transition: Observations from the 1992 Landers earthquake, Geophys. Res. Lett., 23, 20292032, 1996.

Yamano, M., Recent heat flow studies in and around Japan, in Terrestrial Heat Flow and Geothermal Energy in Asia, edited by M. L. Gupta and M. Yamano, pp. 173-201, A. A. Balkema, Rotterda, 1995.

A. Tanaka (e-mail: akiko-tanaka@aist.go.jp) 